\title{
Immigrant Health Inequities: Exposing Diversions and White Supremacy
}

\author{
San Juanita García 1,*(D), Taylor Trummel ${ }^{2}$ (D), Monica Cornejo ${ }^{3}$, Katherine Maldonado ${ }^{4}$, Ana Ojeda ${ }^{5}$, \\ Humberto Flores ${ }^{5}$ and Bruce G. Link ${ }^{6}$
}

check for updates

Citation: García, San Juanita, Taylor Trummel, Monica Cornejo, Katherine Maldonado, Ana Ojeda, Humberto Flores, and Bruce G. Link. 2021. Immigrant Health Inequities: Exposing Diversions and White Supremacy. Social Sciences 10: 341. https://doi.org/10.3390/socsci10090 341

Academic Editors: Pawan H. Dhingra and Tanya Golash-Boza

Received: 23 February 2021

Accepted: 4 September 2021

Published: 13 September 2021

Publisher's Note: MDPI stays neutral with regard to jurisdictional claims in published maps and institutional affiliations.

Copyright: (c) 2021 by the authors. Licensee MDPI, Basel, Switzerland. This article is an open access article distributed under the terms and conditions of the Creative Commons Attribution (CC BY) license (https:// creativecommons.org/licenses/by/ $4.0 /)$.
1 Department of Chicana and Chicano Studies, University of California, Santa Barbara, Santa Barbara, CA 93106, USA

2 Department of Political Science, University of California, Santa Barbara, Santa Barbara, CA 93106, USA; tntrummel@umail.ucsb.edu

3 Department of Communication, University of California, Santa Barbara, Santa Barbara, CA 93106, USA; mrobledocornejo@ucsb.edu

4 Department of Sociology, University of California, Santa Barbara, Santa Barbara, CA 93106, USA; kmaldonado@umail.ucsb.edu

5 Department of Sociology, University of California, Riverside, 900 University Avenue, Riverside, CA 92521, USA; aojed009@ucr.edu (A.O.); hflor008@ucr.edu (H.F.)

6 Department of Sociology, School of Public Policy, University of California, Riverside, 900 University Avenue, Riverside, CA 92521, USA; brucel@ucr.edu

* Correspondence: juanita_garcia@ucsb.edu

Abstract: Diversions occur when research disregards the inequality-generating actions of advantaged groups and instead focuses attention on the actions and behaviors of disadvantaged groups. We incorporate important insights from COVID-19 to illustrate historical and contemporary examples of diversions. This paper highlights US immigrant health inequities-a burgeoning subfield within the broader health inequalities canon-to explore: (1) if and how diversions appear in immigrant health studies; (2) how often white supremacy and intersectionality are explicitly named in grants, publicly available datasets, and published research. The data derive from: NIH R01 grants (17), publicly available datasets that focus on immigrant health (7), and research published in three health journals (14). Using a qualitative content analysis approach, we analyzed these data as evidence concerning the knowledge production cycle, and investigate whether: (a) the role of advantaged groups in generating inequalities is explicitly mentioned; (b) disadvantaged groups are asked about discriminatory actions perpetuated by advantaged groups; (c) health inequalities are placed on the conditions of disadvantaged groups; (d) if white supremacy and intersectionality are explicitly mentioned in grants, publicly available datasets, and research articles. The findings demonstrate the prevalence of diversions in immigrant health research, given an overemphasis on health behaviors and cultural explanations towards explaining immigrant health inequities. There was no mention of white supremacy across the knowledge production cycle. Intersectionality was mentioned once in a research article. We argue that understanding white supremacy's role in the knowledge production cycle illuminates how diversions occur and prevail. We provide suggestions on moving away from diversionary research, toward adopting an intersectional approach of the study of immigrant health inequities.

Keywords: diversions; immigrant health; white supremacy; intersectionality; social determinants of health; COVID-19

\section{Introduction}

"It is not inequalities that kill people ... it is those who are responsible for these inequalities that kill people". (Navarro 2009, p. 423; emphasis on original)

The COVID-19 pandemic has exposed and heightened health and social inequities across the world. In the United States, COVID-19 mortality rates are more than twice as high 
for Black, Latina/o/x, and Indigenous populations, compared to white populations (Egbert and Liao 2020). These high rates are the result of legacies of white supremacy, which have historically, and contemporarily, disenfranchised entire communities, while privileging others. COVID-19 has explicitly brought to the forefront years of disenfranchisement, neglect, and systemic racism, contributing to health inequalities and making certain groups more vulnerable to contracting and dying from COVID-19 (Garcia et al. 2021; Laster Pirtle and Wright 2021). Because of this, we return to the COVID-19 pandemic on multiple occasions throughout this paper to exemplify our concept of diversions.

Health inequalities have been linked with social inequalities. For example, the World Health Organization Commission on the Social Determinants of Health (CSDH) invokes social inequalities as drivers of health inequalities (World Health Organization 2008). Framing health inequalities as deriving from social inequalities leads to medicalizing inequality, and, as Lynch (2017) argues, makes politicians and policy makers able to promote an "equity" agenda, without confronting the fundamental causes of health needed to truly address and eradicate both health and social inequities. Medicalizing inequality ultimately reinforces medical, behavioral, and neoliberal approaches, by allowing politicians and policy makers to hide behind an "equity" agenda, instead of addressing the redistribution of income and wealth (Lynch 2017; Navarro 2009). Policy agendas, such as reparations, and other income and wealth redistribution policies, might better address the fundamental causes of health, getting us closer to a more just and equitable society.

This leads us to our opening quote. Navarro (2009), referring to the WHO Commission on the Social Determinants of Health report, acknowledges and applauds many of its recommendations, but faults it for ignoring the power relations that shape the social determinants of health. The quote hints at the desperate need for explicitly addressing health inequities by describing what is left out, what is emphasized as the culprit for health inequalities, and whether the inequality-generating actions of those in power are considered in health inequalities research. COVID-19 has brought to the fore the historically and systemic rooted inequities that continue to wreak havoc, and further exacerbates the already existing health inequities. Therefore, we incorporate the pandemic to exemplify our concept of diversions, to identify if, and whether, diversions are prevalent in immigrant health studies, and if terms such as white supremacy and intersectionality are explicitly named in immigrant health research.

\subsection{Immigrant Health Inequities}

There are approximately 40 million immigrants in the United States, making it the country with the highest number of immigrants worldwide (Budiman 2020). Mexico is the largest source of immigrants, composing $25 \%$ of all immigrants living in the US (Gonzalez-Barrera and Krogstad 2019). In 2017, there were 11.6 million immigrants from Mexico living in the US, with fewer than half (43\%) of them living as undocumented. The population estimates of the larger undocumented populations in the US suggest that the numbers have decreased, from between 10.9 million and 11.3 million in 2014 to between 10.3 million and 10.7 million in 2017 (Connor et al. 2019).

Among immigrant health inequalities research, there is significant interest in documenting the health of undocumented populations. For example, some of this work highlights how immigrants' exposure to discrimination, resulting from anti-immigrant sentiments, racist practices, anti-immigrant policies, enforcement practices, and a deportation apparatus, negatively impacts their health (Cervantes and Menjívar 2020; García 2018; Kline and Castañeda 2020; Lebrón et al. 2018; Lopez 2019; Mann-Jackson et al. 2018; Morey 2018; Novak et al. 2017; Salas et al. 2013; Vargas et al. 2017). Moreover, another large body of research on undocumented health shows that the undocumented population is legally excluded from receiving and accessing vital services, such as health care, health insurance, food assistance, and other essential services (Park et al. 2017; Perreira and Pedroza 2019; Wallace et al. 2019; for a review of this literature view: Ornelas et al. 2020). In this paper, we bring attention to immigrant health inequities broadly, and, more specifically, to Mexi- 
can undocumented immigrants, who are suffering from the devastations of COVID-19 at alarming rates.

\subsection{Diversions in Immigrant Health Research}

The role of advantaged groups in producing or generating circumstances that lead to health inequities is often omitted from the health inequalities canon of research and policy recommendations. Consequently, advantaged groups continue to reap the benefits of their advantaged positions, which shapes their health in favorable ways. We conceptualize this process, and the cascading results from it, as diversions. Diversions occur when research disregards the actions of advantaged people and shifts the attention toward the circumstances of disadvantaged groups (Link and García 2021). We argue that health inequities research should also ask about the role of advantaged groups and institutions in constructing the mechanisms, pathways, and the fundamental causes of health inequities. Moreover, we argue that overemphasizing disadvantaged groups and asking why they confront worse health outcomes, without a focus on advantaged groups, leads to diversionary research. Omitting advantaged groups from the narrative allows those in power to continue to locate the problem somewhere outside of themselves, thereby protecting their privileged health circumstances. Subsequently, this widens inequities (with no accountability), and perpetuates health inequities.

Words have the power to frame and define inequalities. As such, the ways in which health inequalities are framed define the solutions needed to address them (Lynch 2017; Navarro 2009; Lantz et al. 2007). A diversionary focus that defines the problem as stemming from disadvantaged groups, and of conditions in their communities, will have lasting impacts on the way we create research questions, design research studies, and propose policies to ameliorate inequalities. This will perpetuate social inequities, whereby powerful groups and institutions will continue to get free passes, without any scrutiny into how they might be the culprits in creating health inequities. The way we formulate research questions, the methods and analyses we choose, and, consequently, the way we interpret the findings/results, and disseminate these findings all play a role in how diversionary research can be identified.

To shed light on immigrant health-a burgeoning interdisciplinary subfield, which is gaining more attention due to the COVID-19 pandemic - we ask: (1) if and how diversions appear in immigrant health studies; (2) how often are white supremacy and intersectionality explicitly named? Using various knowledge production venues (including grants, secondary datasets, and research articles), we expose diversions and white supremacy. Before addressing these questions, we provide a historical example of medicalized nativism to illustrate how public health discourse produced racialized constructions of Mexican immigrants as disease carriers. We also provide contemporary examples of how migrants and asylum-seekers are scapegoated and framed as vectors of disease. We use these examples to help illuminate the concept of diversions. Next, we explicate our research questions and research strategy, and describe our findings. We highlight a number of immigrant health studies that produce, what we consider to be, antidiversionary research. Finally, we discuss the relationship between diversions, white supremacy, and intersectionality, and end with suggestions for future research.

\subsection{Historical Example of Diversions: Medicalized Nativism and the 1916 Typhus Outbreak in Los Angeles}

Medicalized nativism (beliefs about the spread of disease by immigrants) is used to justify prejudices against immigrants, to create immigration inspections, and to further justify exclusionary and anti-immigrant views toward foreigners (Kraut 1994; Markel and Stern 1999). Kraut (1994) coined the term, medicalized nativism, to demonstrate how a fear of germs, illness, and disease were attributed to immigrants from the eighteenth and early nineteenth centuries. Engaging in medicalized nativism justified the anti-immigrant policies that continue today. 
Depicting Mexicans in the United States through medicalized terms can be traced back to as early as when the US Southwest was part of Mexico. During the Mexican-American War (1846-1848), an ideology known as Manifest Destiny provided a justification for US expansionism, ultimately giving Anglo-Saxon whites an ability to further colonize the US Southwest. This ideology portrayed white Americans as superior to Mexicans and American Indians. Those promoting this ideology argued that Mexicans and American Indians would not survive because they were not biologically fit (Gómez 2018; Molina 2011). Manifest Destiny aligned with eugenicist logic and biological determinism, or the belief that human behavior is controlled by an individuals' genes. The eugenics movement-a fundamental reality of United States history-used science and education to advance scientific racism (Schwartz 2004; Chavez-Garcia 2012).

Mexican immigration to the US increased, driven by US labor needs, coupled with people fleeing the Mexican Revolution during the 20th century (Markel and Stern 1999; Molina 2011). Mexican sojourner men became the ideal migrant laborers, who traveled temporarily for work but returned to Mexico after work was over. In this period, US immigration laws did not restrict Mexicans because they were filling labor needs by working on the Southern Pacific Railroad and in agricultural jobs (Markel and Stern 1999; Molina 2011). However, soon after medicalized nativism gained dominance, an image of the racially inferior and diseased Mexican became rampant (Molina 2011), negatively shaping how Mexicans were perceived. Molina (2006) documents how public health discourse produced medicalized and racialized constructions of Mexicans and Asians as disease carriers in 1930s Los Angeles. Such discourse, supported and legitimated by "science," reinforced, and further solidified, the earlier stereotypes that were present as a result of the Manifest Destiny ideology, portraying Mexicans as racially inferior, disease carriers, and disease spreaders. With this, we ask: How do diversions become relevant through this historical example? How are the actions of the advantaged, in creating unhealthy conditions, apparent, yet the characteristics of the disadvantaged are framed as the problem? To explicate this even further, we draw on an even more vivid example excavated by Molina's comprehensive archival research (2011).

Documenting the 1916 typhus outbreak in LA County, Molina unearthed the story of a Mexican laborer working at the Southern Pacific Railroad camp who contracted typhus, an infectious disease transmitted to humans through lice and tick bites. What was startling were the responses of their employer and health officials. Over a five-month period, 26 people contracted typhus, including 22 Mexican railroad workers. Despite typhus not being contagious, the inhumane conditions experienced by Mexican laborers, such as overcrowding, poor sanitation conditions, and the lack of facilities to bathe and wash clothes, led to typhus quickly spreading at the camp site.

Public health officials reacted quickly, linking this outbreak to Mexicans and spreading stigmatized conceptions of Mexicans as disease ridden. Continuing on this framing of the problem, health officials reacted aggressively, using cyanide gas to kill lice, ticks, and other pests. The California State Board of Health pressured the employers to take a more direct role in containing the typhus outbreak, leading them to create an eight-point list of regulations, which was printed in both English and Spanish, and shared with various camp sites for all men and their families to see. The Mexican laborers expressed frustration over the attention paid to their individual actions, without any mention of the structural problems in the camps (e.g., lack of toilets and bathing facilities). We share a formal letter of complaint written by several Mexican laborers to the Mexican consul in Los Angeles and excavated by Molina (2011). Below is a portion of this letter:

Dear Sir:

"... We are enclosing a copy of the severe law that the railroad line has imposed on us Mexicans who work on the track, which we do not see as a just thing, but only offensive and humiliating. When we crossed the border into this country, the health inspector inspected us. If the railroad line needs or wants to take such precautions, it is not necessary that they treat us in this manner. For this, they 
would need health inspectors who assisted every individual with medical care and give us 2 rooms to live, one to sleep in and one to cook in, and also to pay a fair wage to obtain a change of clothes and a bar of soap. This wage they set is not enough for the nourishment of one person. Health comes from this and these precautions are the basis for achieving sanitation. Health we have. What we need is liberty and the opportunity to achieve it. We need a bathroom in each section of camp and that the toilets that are now next to the sleeping quarters be moved. Many times their bad smell has prevented us from eating our simple meal. Furthermore, we can disclose many other details which compromise our good health and personal hygiene... "

Felipe Vaiz,

José Martinez

Felipe Martinez

Adolfo Robles

Alejandro Gómez

Alberto Esquivel

(cited in Molina 2011, p. 1026)

We share this letter because it serves as evidence that these courageous men understood that they were being targeted. It also demonstrates their collective efforts in advocating for themselves, their families, and others on the campsite. We witness how diversions occur, whereby public health officials and employers divert attention away from the unhealthy conditions that led to the typhus outbreak, directing it to Mexican laborers' individual characteristics. The regulations focused on improving personal hygiene, and not one addressed the inhumane conditions in the camps. Molina's $(2006,2011)$ outstanding archival research illustrates how diversions were used to shift the blame to Mexicans, scapegoating and stigmatizing them as racially inferior, dirty, and disease spreaders. Such diversions helped justify deportations, pushed for immigration restrictions, and continue to shape how undocumented populations are viewed today.

\subsection{Contemporary Example of Diversions: Framing Migrants and Asylum-Seekers as Vectors of Disease}

New surges of COVID-19 cases, largely motivated by the Delta variant, are being used as ammunition by Republican politicians to frame migrants and asylum-seekers at the US-Mexico border as vectors of disease. The Texas Governor Greg Abbott, Texas Senator Ted Cruz, and Florida Governor Ron DeSantis have all used the recent surge of COVID-19 cases to shift the blame to President Biden's administration for, what they claim to be, lax immigration policies and open borders. Their comments, suggesting that migrants are bringing disease, help resurrect medicalized nativism in present times. More accurately, these examples illuminate that medicalized nativism is not a thing of the past, as we, presently, see how xenophobic and anti-immigrant rhetoric is disguised under "public health" interests, resulting in the exclusion of migrants, refugees, and asylum-seekers.

\subsection{Using Title 42 to Legally Expulse Migrants, Asylum-Seekers, and Children}

The framing of immigrants as vectors of disease is also reminiscent of the toxic rhetoric that Donald Trump and the former presidential administration used to invoke Section 265 of US Code Title 42, to achieve Trump's goal of shutting down the border. In March 2020, Trump invoked Title 42, a provision of US health law that authorizes the Director of the Centers for Disease Control and Prevention (CDC) to issue an "Order suspending the right to introduce certain persons from countries where a quarantinable communicable disease exists" (https: / /www.federalregister.gov / documents / 2020/10/16/2020-22978/order-susp ending-the-right-to-introduce-certain-persons-from-countries-where-a-quarantinable, accessed on 9 August 2021). Despite the CDC's early hesitations to implement Title 42, citing no evidence that such a measure would slow the spread of the virus, the CDC eventually 
implemented Title 42 (Bandler et al. 2020; Dearen and Burke 2020), giving US Customs and Border Protection (CBP) agents the right to "legally" expel migrants seeking asylum, including children.

While several of Trump's immigration policies have been revoked under President Biden's administration, Title 42 continues today. In fact, the use of Title 42 has increased under Biden's administration, resulting in the expulsion of individuals, families (including single mothers with children (U.S. Customs and Border Protection 2021), and even the expulsion of more than 20 babies and children to Haiti (Pilkington 2021). Community organizations, activists, and public health experts across the United States from public health schools, medical schools, and other academic institutions have expressed outrage, calling on Biden's administration to rescind Title 42 (https: / / www.humanrightsfirst.org/s ites/default/files/LetteronDHSExpulsionsUnderCDCOrder.pdf, accessed on 10 August 2021); https: / / www.publichealth.columbia.edu/research/program-forced-migration-an d-health/letter-acting-hhs-secretary-cochran-and-cdc-director-walensky, accessed on 10 August 2021). Their message is clear: Title 42 is not about protecting public health; instead, it spreads, masquerades, and disguises xenophobia as a public health measure. Various lawyers and United Nations officials have similarly opposed Title 42, arguing that it violates US and international laws (Guttentag 2020; UN High Commissioner for Refugees 2020).

In this contemporary example, migrants and asylum-seekers are scapegoated and blamed for spreading disease, similar to the way Mexican immigrants were framed as spreading typhus. Both the rhetoric put forth by the Texas and Florida governors, and echoed by other Republican politicians, and the implementation of Title 42, reveals diversions in two ways. First, these men frame migrants and asylum-seekers as vectors of disease, helping resurrect medicalized nativism. Doing so diverts attention from their own behavior, promoting personal freedom to justify their reasoning for not mandating masks and vaccines, defying public health recommendations and scientific evidence that shows how masks and vaccines help constrain COVID-19 and save lives. Second, these men are using such framing for their own political gains, and diverting attention away from the role the United States has played, in Central America and Mexico, in creating the conditions that force people to seek refuge in the US. Capitalism, wars, and climate change have largely driven mass migration, creating what Walia (2021), a Canadian activist, has described as "global apartheid."

These historical and contemporary examples demonstrate the need to identify diversions in the broader immigrant health research. The COVID-19 pandemic has underscored how migrants are stigmatized as a public health threat, diverting attention away from the role that advantaged groups and powerful institutions play in the generation of inequalities that lead to health inequities. We strongly believe that identifying diversions in the knowledge production cycle of immigrant health research will bring visibility to the role that advantaged groups and institutions play in generating immigrant health inequities. We are also interested in understanding if white supremacy and intersectionality are explicitly named in grants, secondary datasets, and research articles.

\subsection{Explicitly Naming White Supremacy in Health Inequalities Research}

There has been a significant increase in research highlighting the various ways in which racism negatively affects health (Ford and Airhihenbuwa 2010; Hardeman et al. 2018; Jones 2002, 2016; Phelan and Link 2015; Williams et al. 2019; Williams and Mohammed 2013). However, it was not until 2021 that the Centers for Disease and Control (CDC) recognized racism as "a serious public health threat" (CDC and HHS 2020a, 2020b). Sparked by police violence and the health inequities that COVID-19 has brought to bear, Rochelle P. Walensky, the CDC Director stated "Yet the disparities seen over the past year were not a result of COVID-19. Instead, the pandemic illuminated inequities that have existed for generations and revealed for all of America a known, but often unaddressed, epidemic impacting public health: racism" (CDC Newsroom 2021). This has initiated the CDC's efforts for bringing racism, as a fundamental cause of health inequities, to the forefront, by introducing 
various initiatives. For example, they have launched a new web portal, Racism and Health, which serves as a hub to illustrate CDC's commitment to ensuring all people live healthy lives. The web portal features publications from the CDC and from researchers that study racism and health (https:/ / www.cdc.gov/healthequity/racism-disparities, accessed on 2 September 2021). The National Institutes of Health (NIH) has similarly pledged support toward ending structural racism and racial inequities in biomedical research. For example, the NIH has established the UNITE initiative to address structural racism and promote racial equity and inclusion within the biomedical research enterprise and within the NIH as an institution (https://www.nih.gov/ending-structural-racism/unite, accessed on 12 August 2021).

Explicitly naming racism among these top government health agencies is an important first step. While white supremacy, a system of dominance built through multiple stages of colonial conquest, genocide, and imperialism (Mills 1997; Smith 2012a), is linked with racism, studies that explicitly name white supremacy are still rare. Yet, white supremacy and its connection to health can be understood by Du Bois (1935) work on the "public and psychological wage" that is accrued from whiteness. For example, Du Bois explains how poor whites benefited from their identification and commitment to whiteness, leading to better rewards, privileges, and benefits accumulating from early life, throughout the entire course of life.

The more recent work on health inequities has focused on the social determinants of health, to help illuminate how the conditions in which people are born, grow up, live, work, and age are shaped by social, political, and economic forces (World Health Organization 2008). However, most of this work has focused on understanding the social determinants of health among disadvantaged groups, given their social positions and higher exposures to social conditions that are linked to poor health. More recent work, however, has empirically examined how white privilege shapes health (Kwate and Goodman 2014). With a focus on whiteness, Malat et al. (2018) developed a framework that illustrates multiple pathways of how whiteness affects whites' health. Accordingly, framing whiteness as a racialized social system serves as a theoretical tool to understand how US whiteness and capitalism shape societal conditions, individual social characteristics and experiences, and psychosocial responses, and their impacts on whites' health. Using social policies supported by whiteness, beliefs and narratives of whiteness, and the privileges of whiteness to guide their analyses, the authors highlight how whiteness can sometimes lead to negative health consequences, and other instances in which whiteness may lead to positive health.

\subsection{Diversions and Connections to White Supremacy}

The concept of diversions aligns with Malat et al.'s (2018) framework, but it explores a distinct area. We agree that systems of racial inequity and class inequities affect health, and that people in disadvantaged positions have more exposure and fewer resources to protect them from deleterious health conditions. However, our work on diversions encourages researchers to ask: What causes or creates these health inequalities? What are the inequality-generating behaviors that advantaged groups and institutions play in shaping health inequalities? Why do we ignore the role that advantaged and powerful institutions play in shaping health? What are the consequences of diversionary research, for both advantaged and disadvantaged groups? We see white supremacy as a culprit that creates, fosters, shapes, and perpetuates diversionary research.

\subsection{Explicitly Naming White Supremacy in Immigrant Health Inequities Research}

More strides have been made in bridging the sociology of race and critical race scholarship with migration studies (García 2017; Golash-Boza et al. 2019; Romero 2008; Sáenz and Douglas 2015; Treitler 2015). White supremacy is explicitly named to expose how assimilation perspectives support white supremacy by ignoring how immigrants are racialized. Asad and Clair (2018) conceptualize racialized legal status (RLS), a social position 
based on supposed race-neutral legal classifications, that disproportionately affects People of Color, and provide a framework that demonstrates how RLS shapes health disparities.

More recent research suggests that understanding immigration as both socially determined and as a social determinant of health is vital (Castañeda et al. 2015). Immigration is shaped by the social determinants of health in two ways. Firstly, social determinants (such as poverty, persecution, wars, etc.) push people to migrate. Secondly, social determinants affect the lives of immigrants as they settle into their new lives. Nevertheless, the extensive immigration and health literature within the broader public health field has overwhelmingly emphasized behavioral and cultural frameworks over structural frameworks (for an excellent review, see: Castañeda et al. 2015).

\subsection{Dominant Frameworks to Understand Immigrant Health}

Behavioral frameworks focus on individual health behaviors (e.g., smoking, drinking, and dietary habits) as the primary units of analysis. Consequently, theories and interventions that focus on behavior change are proposed, and the onus is placed on the individual (and, generally, on disadvantaged individuals) (Castañeda et al. 2015; Viruell-Fuentes et al. 2012). This perpetuates the deficit perspectives that place the onus on disadvantaged groups and their presumed lack of responsibility, ability to be educated, and motivation for making healthy choices. As such, this framework does not contextualize or address the structural conditions impinging on immigrants' lives (Castañeda et al. 2015). Similarly, cultural frameworks make comparable erroneous conclusions about immigrant health.

Cultural frameworks are considered to be the second most common approach to understanding immigration and health within the public health literature (Castañeda et al. 2015). These works emphasize cultural practices, such as group traits, customs, beliefs, traditions, and values. Cultural practices shape the individual behaviors that then shape health (Castañeda et al. 2015; Viruell-Fuentes et al. 2012). This framework supports research on the Latina/o/x Health Paradox which suggests that, while immigrant cultural practices are championed and viewed as protective, they likely also lead to homogenizing Latina/o/xs (Sáenz and Morales 2012).

The final framework that Castañeda et al. (2015) identify is a structural framework. The structural framework acknowledges larger social factors and their impacts on health. The scholarship exploring how 'illegality' and anti-immigrant policies shape health fall under this framework. The structural framework also aligns closely to a social determinants of health approach.

\subsection{Diversions and Connections to Dominant Frameworks to Understand Immigrant Health}

We argue that the behavioral and cultural frameworks align with our concept of diversions, as they shape a narrative that places the onus on immigrants' individual choices, without considering structural factors, and without explicitly addressing how advantaged or powerful institutions shape immigrant health. Perhaps it is not surprising that diversions are prevalent in the immigrant health literature, given that this subfield builds on the broader health inequalities research. However, the immigrant health literature has not been examined systematically across the various stages of the knowledge production cycle.

\section{Research Strategy}

Data were derived using a systematic method to gather and analyze content from multiple sources. We combined data that was part of a larger study with new data sources to explore whether diversions appear in immigrant health research. More specifically, data derived from (a) grants focusing on migration and health that have been funded through the National Institutes of Health (NIH R01) during the 5 year period 2015-2019); (b) largescale and nationally representative datasets that are publicly available and that focus on migration and health; (c) published articles that center on migration and health. Graduate Research Fellows (GRFs) took the lead in data collection and analysis, with guidance from 
first and last authors. This study was exempt from institutional review board approval, given that the analysis did not involve human subjects.

Adopting a qualitative content analysis approach, we analyzed the content of grants, secondary datasets, and research articles, and engaged in an iterative coding process to identify if diversions appeared across the knowledge production cycle, and if terms and concepts such as white supremacy and intersectionality were explicitly named. We specifically used two types of content analyses: directed and summative content analysis. Directed content analysis takes a deductive approach in that the coding tool and the coding categories are developed based on previous research or theory (Hsieh and Shannon 2005). We used directed content analysis to examine whether diversions exist in immigrant health studies, in grants, secondary datasets, and published research. Summative content analyses involve documenting counts, frequencies, and comparisons, of keywords, terms, or content, followed by the interpretation of the underlying context (Hsieh and Shannon 2005). We used summative content analysis to examine if white supremacy and intersectionality were explicitly mentioned, across all stages of the knowledge production cycle.

To explore our research questions, we turned to three categories of evidence at each stage of the knowledge production process that served to guide the development of our coding tools and coding process. First, we identified whether direct inequalitygenerating actions of advantaged groups were represented. Second, we identified whether indirect accounts appeared, by determining if disadvantaged groups described the inequalitygenerating actions of advantaged groups. Third, we identified whether, instead of a focus on advantaged groups, attention locates the problem in disadvantaged groups. Evidence consistent with the diversions concept would show relatively little attention focused on advantaged groups and relatively more attention directed to the characteristics and conditions experienced by disadvantaged groups. This research strategy allowed us to find evidence to investigate whether diversions occurred. If the evidence, across all stages of the knowledge production cycle, reveals an underrepresentation of studies that focus on advantaged groups, then we will know that diversions are prevalent. Before highlighting the results, we first explain what we mean by two key terms: advantaged and disadvantaged.

By advantaged, we mean those that are socially privileged by their racial and economic position within the United States' social hierarchy. For example, white people are considered advantaged, racially. Economically, we refer to people with higher income and wealth. Given that we are focusing on immigrant health research, advantaged people have US citizenship and/or legal status. For example, those that have citizenship, speak English, are white, and have higher income are considered the most advantaged. Individuals that meet these criteria are considered socially advantaged and have favorable social, economic, or political conditions. Moreover, they face fewer barriers to access health care, and do not experience the same environmental and occupational health hazards as the disadvantaged. Advantaged people will have more flexible resources of knowledge, money, power, and prestige, and beneficial social connections that can help them garner health advantages (Link and Phelan 1995; Phelan and Link 2015), than disadvantaged groups.

In contrast, by disadvantaged, we mean those that are socially underprivileged by their racial and economic position within the United States racial hierarchy. For example, Black, Indigenous, People of Color (BIPOC) that experience socio-economic disadvantage are considered socially disadvantaged. We are also interested in shedding light on undocumented immigrant populations, given that they are not able to reap the benefits of their labor. Socially disadvantaged groups confront unfavorable social, economic, or political conditions given their relative position in social hierarchies. People that make up this category experience low levels of wealth, income, and education, low-wage employment, and less political representation (Braveman et al. 2011). The health inequalities that these groups confront are created by a variety of life experiences, such as environmental racism, discrimination, language barriers, fears of the government and police, food deserts, poor infrastructure, poverty, and much more. Furthermore, many individuals experience several of these compounding disadvantages, leading to a society where the socio-economically 
advantaged continue to have more privileges and opportunities to improve their health care and personal health.

\section{Results}

\subsection{National Institute of Health R01 Research Grants 2015-2019}

Using the NIH Research Portfolio Online Reporting Tools (RePORTER), that provides "access to reports, data, and analyses of NIH research activities, including information on NIH expenditures and the results of NIH-supported research," we identified National Institutes of Health (NIH) R01 equivalent grants, ranging from the fiscal year of 2015 to 2019. We searched for new and competing renewal project grants identified as R01 equivalents (DP2, R01, R23, R29, R37, RF1). The project grants were limited to immigrant health search terms, required in one of the following: project title, project terms, or project abstract. To extract grants related to immigrant health, the search for immigrant health terms were two-fold. First, we searched eight status terms individually (undocumented, unauthorized, illegal, citizenship, migrant, nativity, immigrant, and citizen), along with three health terms (health disparities, health inequalities, health inequities) using the NIH RePORTER platform. The second round of search terms consisted of the term "immigrant" combined with variations on the word "health" (undocumented and health, unauthorized and health, illegal and health, citizenship and health, migrant and health, nativity and health, immigrant and health, or citizen and health) with disparities, inequalities, and inequities. The results from the two-fold search yielded 36 grants. After removing duplicates, 31 remained. To ensure the grants focused on researching immigrants and health, we read the title, abstract, and the public health relevance statement, to determine if the studies were motivated to understand immigrant health, and did not simply mention the search terms. After examining each grant, and determining if the focus was on immigrant health, 17 grants remained for the final analysis in this paper.

\subsection{Actions of Advantaged People}

We examined whether any of the 17 grants concentrated directly on the actions of advantaged people - based on race/ethnicity, socioeconomic status, nativity, legal status (undocumented/documented status) - to determine whether any aspect of their behavior was considered as a possible contributor to health inequalities. Analyzing the content from the title, abstract, and public health relevance statement, we found one grant that focused on the actions of advantaged people. This grant focused on the effects that state policies have had on immigrants' access to health care. Furthermore, to understand if the grants focused on studying how the actions of advantaged people affect immigrant health, we coded to identify if any of the following terms were mentioned: colonialism, white supremacy, intersectionality, white racism, structural racism, settler colonialism, neoliberalism, and imperialism. These terms were not found in any of the 17 grants we identified.

\subsection{Reports from Disadvantaged People That Reflect on the Behavior of Advantaged People}

The grants were analyzed for terms that might be creating health inequalities in immigrant communities, such as family separation, deportation, stigma, exploitation, disrespect, harassment, and discrimination. We found that five of the 17 grants discussed the following: one family separation, one exploitation, one harassment, and three discrimination. One of the five grants discussed both family separation and discrimination. For grants that mentioned discrimination, we further searched if these terms were discussed in the aims of the grant. Based on the three grants that mentioned discrimination in the title, abstract, or health relevance statement, only one grant discussed discrimination in the project's aims. This study focused on understanding if discrimination, along with psychological factors, were related to Type 2 diabetes. 


\subsection{Concepts and Conditions That Locate the Problem in Disadvantaged Groups}

To further understand the discussion of health inequities amongst immigrant groups, we coded for the same two concepts and conditions that were coded in a previous health inequalities diversions study (Link and García 2021). The two concepts coded in the grants were (1) health behaviors and (2) biomarkers/genetics/epigenetic factors. Discussions of health behaviors were found in 16 of the 17 grants. The grants discussed social networks/support, immigrant, cultural, and linguistic factors, coping, acculturation, substance abuse/dependence, and social isolation. The analysis of biomarkers, genetics, and epigenetics was not as common as behaviors, but they were mentioned in seven of the 17 grants, through discussions of biomarkers, blood/urine samples, inflammation, blood pressure, and biospecimens.

To summarize, we found one grant that focused on the actions of the advantaged (policies on immigrants' access to health care). There was no mention of white supremacy, colonialism, white racism, structural racism, settler colonialism, neoliberalism, or imperialism; all terms which address the conditions that immigrants confront and that have health implications. Our coding also explored if the term intersectionality was explicitly mentioned; however, we did not find any grants that did so. In identifying whether the reports from disadvantaged people reflect the behavior of advantaged groups, we found that only five of the 17 grants did so, and that only one included discrimination as a primary aim. Given that 16 of the 17 grants mentioned concepts and conditions that locate the problem in disadvantaged groups, such as through health behaviors, cultural practices, or acculturation, provides evidence of diversions occurring.

\subsection{Major Health Datasets Publicly Available for Secondary Analysis}

We identified large, publicly available, nationally representative studies that focus on migrant health. To do this, we (1) did a broad search to find publicly available secondary datasets, including through the Inter-university Consortium for Political and Social Research (ICPSR), with keywords such as migrant health, immigration health, and foreignborn health, and (2) searched through the 14 research articles included in this study to examine the datasets that were used in those studies. Our inclusion criteria included datasets that were longitudinal studies with multiple waves of data collection, or studies that involved multiple cross-sectional assessments conducted in the US. We found a total of 11 datasets, although four were excluded because data collection occurred only once.

We analyzed seven datasets; four longitudinal and three cross-sectional datasets. The longitudinal datasets we examined were (1) the National Institutes of Health's Hispanic Community Health Study/Study of Latinos (HCHS/SOL); (2) the New Immigrant Survey (NIS); (3) the Mexican Family Life Survey (MxFLS); (4) The National Longitudinal Study of Adolescent to Adult Health (ADD Health). The multiple cross-sectional studies we examined were the (1) National Health Interview Survey (NHIS); (2) Mexican Migration Project (MMP); (3) National Health and Nutrition Examination Survey (NHANES).

From the seven datasets, four datasets (SOL, NIS, MMP, MxFLS) focused on migrant health, and three were national health datasets with migrant populations included (ADD Health, NHANES, NHIS). The four additional datasets that were excluded from our sample are one-time cross-sectional studies that focus primarily on migrant health. These are the (1) National Latino and Asian American Study (NLAAS); (2) National Survey of American Life (NSAL); (3) National Latino Health and Immigration Survey (NLHIS); (4) American Health Values Survey (AHVS). For each dataset in our sample, we examined the content from the survey instruments and protocols, including the codebooks for each study.

\subsection{Actions of the Advantaged}

None of the datasets had a theme focusing on the health inequality generating actions of advantaged people. There were no questions that focused on immigration policy impacts, the behavior of government officials that affect health, the behavioral intentions regarding wanting to keep migrants out of neighborhoods, schools, and jobs, and no measures on the 
implicit biases toward migrant communities. The term white supremacy did not emerge among the databases used. There were no questions that focused on US imperialism, neoliberal policies, or settler-colonialism; all conditions that push people to migrate to new countries (Speed 2019).

\subsection{Reports from Disadvantaged People That Reflect on the Behavior of Advantaged People}

Within the seven major databases reviewed, there was no inclusion of measures of discrimination related to class or racial discrimination, or being perceived as undocumented or an immigrant (see Supplemental Table S1). These datasets did not include measures of microaggressions, ethnic pride, racial socialization, or implicit bias. The governmentsponsored repeat cross-sectional studies (NHIS, MMP, NHANES) were particularly sparse in their coverage of discrimination. The range in their minimal coverage was from none (NHANES) to the MMP that included one question on mistreatment as a migrant in the US. The NHIS lies in between, where it included sponsored supplements over the past 20 years, in which one out of the 169 questions was about health care providers (related to cultural competency).

The longitudinal studies that we reviewed produced similar results. The SOL study includes two questions on perceived discrimination. The ADD Health study includes one single item from Williams' Everyday Discrimination Measure in Wave 4 (2008), 14 years after the study began, and added four more items from Williams' Everyday Discrimination Measure in Wave 5. However, these additional items did not explicitly ask if the discrimination was based on undocumented status, presumed undocumented status, class, or racial background. The MxFLS and NIS do not focus on questions of discrimination. Overall, none of these studies include measures that specifically address the exploitation or racism that migrants in the US might experience, despite the various studies that have noted the importance of discrimination and anti-immigration policies on health. Only the MMP includes one question about treatment as a migrant worker in the US. However, this question does not capture who is doing the mistreatment, who is discriminating, or who is the perpetrator(s).

\subsection{Concepts and Conditions That Locate the Problem in Disadvantaged Groups}

All of the studies focused on self-reported health behaviors, traits, and biomarkers (see Supplemental Table S1). For example, health behaviors included smoking, drinking, exercise, sleep quality, diet, and personality traits, such as cognitive skills. All of the studies included health behaviors, and four out of the seven included biomarkers. The focus on concepts and conditions that locate the problem in disadvantaged groups redirects the attention away from advantaged groups and, thus, provides evidence of diversions.

To summarize, none of the datasets focused on the actions of the advantaged. The term white supremacy was not identified in any of the datasets. We did not find intersectionality explicitly mentioned in the datasets. In identifying whether the reports from disadvantaged people reflect the behavior of advantaged groups, we found no discrimination measures related to class and racial discrimination, or being perceived as undocumented or an immigrant. The MMP had one question on mistreatment as a migrant in the US, although questions that capture who is discriminating are not included. The NHIS asked one question, over the past 20 years, about respect by health care providers. All of the studies focused on health behaviors, traits, and biomarkers, and locate the problem in disadvantaged groups. These findings indicate a rerouting of the inequality-generating actions of the advantaged, which is indicative of diversions.

\subsection{Health Inequalities Empirical Research Published in Three Major Journals 2014-2019}

Immigrant health-related articles were chosen from a large sample of 324 articles, derived from three major journals (American Journal of Public Health, Journal of Health and Social Behavior, and Social Science and Medicine-Population Health), given their strong emphasis on health inequalities. We used a systematic literature review methodology to 
identify US-focused empirical articles, published from 1 January 2014 to 30 June 2019, that mentioned the following terms: health disparities, health inequalities, or health inequities. For this paper, we used articles from this larger study to identify the articles focusing on immigrant health.

The eligibility criteria included articles that: (a) mention one or more of the following keywords and/or their inflections: immigrant, migrant, or foreign; (b) focused on the United States. This reduced our sample to 34 articles. Next, these 34 articles were reviewed independently, as to whether the article addressed immigrant health disparities as the focus of the paper. To identify this, three Graduate Research Fellows skimmed the 34 articles to assess whether the topic of study was driven by an immigration focus, or whether it was merely tangentially mentioned. This process yielded 14 articles that focused on immigrant health inequalities and were, thus, used for the analysis.

After identifying these 14 articles, the GRFs coded the articles utilizing the following open- and closed-ended criteria: (1) explanatory focus on disadvantaged populations (does the article use aspects of the disadvantaged/unprivileged groups to explain why health disparities exist? For example, Traits, Behaviors, Attitudes, Genes, Biomarkers, Cultural Orientation, Resilience, or Conditions of Neighborhood); (2) explanatory focus on advantaged populations (does the article use aspects of the advantaged/privileged groups to explain why health disparities exist? For example, Traits, Behaviors, Attitudes, Genes, Biomarkers, Cultural Orientation, Resilience, or Conditions of Neighborhood); (3) advantaged groups involved in creating inequalities (does the article mention whether advantaged groups may be involved in creating inequalities in health, between advantaged and disadvantaged groups?); (4) measurement of discrimination (does the article include an explicit measure of discrimination? For example, Major Experiences, Everyday Discrimination, Heightened Vigilance, Micro-aggressions, Perpetration of Discrimination, Implicit Bias, or Anticipatory Discrimination); (5) naming oppression (does the article explicitly mention: racism, systemic racism, institutionalized racism, white racism, white supremacy, colonialism, exploitation, or domination?); (6) structural inequities (does the article specify the structural inequities, or the systemic disadvantage, of one social group compared to other groups with whom they coexist (such as redlining, mass incarceration, the prison-industrial complex, and the immigration-industrial complex), and how they lead to health inequities?); (7) structural systems (does the article explain that health disparities exist because of larger systems or institutions?); (8) intersectionality (does the article explicitly name or reference intersectionality?). In addition to these criteria, coders were also instructed to write notes on anything that stood out in the articles related to diversions.

Using the coding criteria, the coders read and coded five articles each week, for a total of three weeks. After individually coding each article, the three coders met weekly for one and a half hours to discuss their coding and settle any disagreements. While disagreement was not common, when it did emerge, the coders talked about the disagreement and referenced the article until a consensus was reached.

\subsection{Actions of the Advantaged}

Our findings indicate that four articles focused on the advantaged populations to explain why health inequalities exist (Wallace et al. 2019; Martínez et al. 2018; Rodriguez 2019; Minkler et al. 2014, see Supplemental Table S2). First, the citizenship of advantaged people functions as a source that contributes to creating health inequalities. For example, Wallace et al. (2019) proposed that state policies create space for health inequalities among undocumented and documented immigrants, because advantaged people are granted more resources than undocumented immigrants. Wallace et al. (2019) also highlight that undocumented immigrants are more likely to be racially profiled, which can create stressors. In addition, they describe that various political institutions create environments that disadvantage undocumented immigrants. They describe five distinct state policy domains: "health and welfare benefits, higher education, labor and employment, driver's licenses and IDs, and immigration enforcement" (p. 2). 
Similarly, to Wallace et al. (2019), Martínez et al. (2018) focused on using aspects of the advantaged to explain why health inequalities exist. More specifically, Martínez et al. (2018) proposed that the implementation of immigration enforcement policies (IEP) generates health inequities for undocumented immigrants via their persecution. They explain that IEP creates fear and mistrust among immigrant communities, particularly Latinos, which results in "Latino and Mexican-origin families to evade services from government agencies, despite their children qualifying for them" (p. 189). Additionally, Martínez et al. (2018) highlight that IEP are part of institutionally racist systems. In explaining health disparities, Rodriguez (2019) spotlights various political and historical events that have driven health outcomes, such as the Jim Crow era and the Civil Rights Movement. This puts some of the accountability for poor infant mortality rates on political institutions. Minkler et al. (2014) avoid diversions by including employers and wage theft as issues contributing to health inequalities. For more details on these exemplar articles, see Supplementary Table S2.

\subsection{Reports from Disadvantaged People That Reflect on the Behavior of Advantaged People}

None of the 14 articles included a measure of discrimination in their assessment of health inequalities. Ten of the 14 articles analyzed focused on the disadvantaged when explaining health inequalities. Among these 10, some still mentioned some forms of structural barriers, but failed to make connections from this to a greater explanation of immigrant health inequalities. For example, one article (Landale et al. 2015) explains the health inequalities between children of immigrants with varying legal status. However, the focus is on the parents' undocumented status as a major factor in determining the children's health outcomes. This approach places the responsibility of the disparity on the undocumented parents, and does not go far enough in explaining the advantaged role in creating the conditions for citizenship status, as a determinant of children's health. An exemplary quote from this article states that: "Mexican-origin youth with undocumented mothers have significantly higher levels of internalizing and externalizing behavior problems than their co-ethnic counterparts with documented or naturalized citizen mothers. Thus, treating Mexican children with immigrant parents as a single undifferentiated group masks important differences in outcomes by parental legal status." While it is important to emphasize the varying differences within immigrant groups, it is crucial to acknowledge why undocumented status is detrimental to these children (i.e., limited access to health care, poor health care treatment, discrimination, fear of deportation). Advantaged groups enforce the conditions created for undocumented immigrants in the United States.

\subsection{Concepts and Conditions That Locate the Problem in Disadvantaged Groups}

Although some articles focused on the advantaged to explain health inequalities, most of the articles used an explanatory focus on disadvantaged populations to explain them. For example, several of the articles, and two in particular (Warner and Swisher 2015; Gany et al. 2015), named aspects of oppression and/or structural barriers, but ultimately focused on the disadvantaged in their explanations. Ten articles explain health disparities by focusing on the disadvantaged. Four articles, however, focused on the advantaged (see Supplementary Table S2). While there were only four that ultimately explained health inequalities by focusing on the actions of the advantaged, several other articles do mention forms of oppression and/or structural barriers. Generally, there is overlap between articles that focused on the advantaged in explaining why health inequalities exist, and in naming the advantaged as the creators of the inequalities, oppression, structural inequalities, and structural systems. Of the 14 articles analyzed, none included the terms white supremacy, systemic racism, white racism, or domination. One article (Warner and Swisher 2015) included the term intersectionality; however, it ultimately shifted its focus to the behaviors of the disadvantaged.

The overwhelming lack of grants, datasets, and articles that focus on the advantaged directly, or by asking disadvantaged groups about the discrimination or exploitation they have experienced (targeting the inequality-generating actions of the advantaged indirectly), 
and an overemphasis on the conditions that locate the problem in disadvantaged groups, are indicative that diversions are prevalent. The lack of related terms, such as white supremacy, mentioned is also problematic. Across the knowledge production cycle, we found that zero grants, datasets, and articles mentioned the term white supremacy. One article mentioned the term intersectionality. We argue that this provides evidence that diversions are occurring across the knowledge production cycle.

\section{Discussion}

Throughout this paper, we have argued that diversions capture a shifting away of the inequality-generating actions of advantaged groups toward the conditions of disadvantaged people. This paper stems from a larger research project on health inequalities and diversions. Motivated by how immigration policies, deportation threats, systemic racism, and other structural factors shape the health and lives of immigrants and their families, coupled with the current pandemic ravaging BIPOC communities, we sought to identify whether diversions were common, and if white supremacy and intersectionality were explicitly mentioned in grants, datasets, and published articles. We provided historical and contemporary examples of medicalized nativism to reveal the detrimental consequences of diversionary logic. Using various stages of the knowledge production cycle, grants (17), large-scale datasets (7), and published research articles (14), we exposed diversions and white supremacy. We found an overwhelming lack of grants, datasets, and articles that focus on the advantaged directly, or by asking disadvantaged groups about discrimination or exploitation they have experienced (targeting the inequality-generating actions of the advantaged indirectly), and an overemphasis on conditions that locate the problem in disadvantaged groups. Our findings expose how pervasive diversions are, and depict the hesitancy of explicitly naming white supremacy and intersectionality across all stages of the knowledge production cycle.

\subsection{Diversions and White Supremacy}

We argue that white supremacy helps create, produce, and reproduce diversions. We ask: where does the hesitancy of explicitly naming white supremacy in immigrant health studies come from? The lack of even mentioning white supremacy, or even systemic racism, blurs the power structures dictating the potential solutions proposed for addressing immigrant health inequities, without holding those in power accountable. Ultimately, this limits radical transformation within, and outside, health institutions, and continues the cycles of exacerbating inequities, as COVID-19 has laid bare.

While few studies acknowledge whiteness and white privilege in examining whites' health, we argue that more studies should bring to the fore the role white supremacy plays in understanding its effects on people's health, the ways in which white supremacy seeps into social institutions and impacts everyday interactions, shaping access to, and the quality of, health care. It is critical to acknowledge white supremacy's role in structuring all social institutions, including immigration and health systems, as well as the role that advantaged groups play in contributing to health inequities. Perhaps some of the hesitation with explicitly using the term white supremacy is due to whites' fragility in acknowledging how they benefit from whiteness.

In the words of Mills (2003): "Since official segregation and explicit political exclusion of this sort no longer exist in the United States, the term has now disappeared from mainstream white American discourse. If it is employed at all, it is only to refer to the unhappy past or, in the purely ideological and attitudinal sense, to the beliefs of radical white-separatist groups (i.e., as white supremacists). That in important ways the United States could still be white supremacist would, of course, be rejected out of hand." (p. 36). White supremacy, he argues, must be conceptualized in much broader terms, beyond the narrowly juridical way. White supremacy requires a deeper understanding of how domination and race connects to structural and individual violence, and exploitation, 
is needed. Critical race scholar Ansley (1989) developed two possible models of white supremacy, including a "class" and a "race" model. In Ansley's words:

"By "white supremacy" I do not mean to allude only to the self-conscious racism of white supremacist hate groups. I refer instead to a political, economic and cultural system in which whites overwhelmingly control power and material resources, conscious and unconscious ideas of white superiority and entitlement are widespread, and relations of white dominance and non-white subordination are daily reenacted across a broad array of institutions and social settings." (p. 1024)

Framing white supremacy as a system of dominance that is deeply ingrained in all social institutions, with historical roots that continue to be felt, reenacted, and reinvented in newer (often hidden) ways is important to recognize. White supremacy, with its deep roots from colonial conquest, genocide, and imperialism, must be exposed in the health inequalities research and the immigrant health literature. We argue that white supremacy helps sustain diversions throughout the knowledge production cycle. These findings leads us to ask: How can we create antidiversionary research? Incorporating a social determinants of health and intersectionality framework to immigrant health studies provides an avenue toward antidiversionary research. A social determinants of health framework, one that highlights how upstream social determinants of health (e.g., economic and political structures, social and physical environments) shape the pathways that lead to immigrant health inequities is desperately needed (Castañeda et al. 2015; Wallace et al. 2019). However, Navarro (2009) reminds us of the importance of casting light on the power relations that shape the social determinants of health, even among studies that aim to elucidating the social determinants of health. Adopting an intersectional approach toward understanding the social determinants of health allows researchers to shine a direct light on power relations (Hankivsky and Christoffersen 2008; López and Gadsden 2016).

\subsection{Intersectionality and Immigrant Health: Toward Antidiversionary Research}

Viruell-Fuentes $(2007,2011)$ and Viruell-Fuentes et al. (2012) pioneering work has shaped immigrant health research in significant ways. Her work is an example of antidiversionary research, as she identified the problems associated with the individual behavioral and cultural frameworks that are commonly used to study immigrant health. Encouraging immigrant health scholars to embrace an intersectional lens, Viruell-Fuentes et al. (2012) argued that:

“... intersectionality theory can serve as a guiding framework in shifting the focus away from individual-level conceptualizations of culture in immigrant health research, to structural examinations that take into account the power dimensions of race, class, gender, and immigrant status hierarchies and how these shape inequities." (p. 2100)

An intersectionality approach to immigrant health inequities is necessary in order to move away from diversionary research. Black activists and scholars first developed intersectionality to illustrate how Black women endured oppression, due to both their race and gender social positions, and, thus, argued that these two social positions should not be treated separately (Crenshaw 1989, 1991; Combahee River Collective 1983). Sociologist Patricia Hill Collins (2015) views intersectionality as an analytical strategy in illustrating how social categories, such as race, class, gender, and sexuality, are mutually constructed and shaped by intersecting systems of power that produce social formations of complex social inequities. Intersectionality provides a strong analytical tool for understanding health inequalities beyond racial, ethnic, and socioeconomic social positions by addressing multiple layers of privilege and disadvantage (Gkiouleka et al. 2018; Hankivsky and Christoffersen 2008; López and Gadsden 2016). What links diversions with intersectionality is the attention to systems of power (e.g., white supremacy, nativism), and how they may be producing health inequities. 


\subsection{Limitations}

Although insightful, our findings have several limitations. First, in our selections of NIH R01 grants, we decided to focus on grants in the past 5 years, and not on all grants funded. Additionally, although we examined major publicly available longitudinal and multiple cross-sectional datasets that are used as secondary data sources, we excluded cross-sectional studies that took place once. The research articles were selected from a larger study focused on diversions and health inequalities. This study yielded 324 articles from three prominent health journals. From the 324 articles, we identified research focused on migration and health, and after ensuring all inclusion criteria were met, we were left with 14 articles to analyze for this paper. A limitation is that the articles derive from the 324 articles available. Yet, the low number of results from both the larger study to the 14 articles we analyzed in this paper demonstrates how immigrant health research deserves more attention.

\subsection{Future Research}

Future research should explore if diversions or diversionary logic appear in other social domains beyond health inequalities and immigrant health inequities. For example, how is the recent attack on Critical Race Theory framed as diversionary? How do universities perpetuate diversions when faculty of color, queer, or other minoritized faculty are pushed out of their workplaces? How do policy makers use diversions in promoting voter suppression? How do policy makers advocate for policies aimed to constrain the spread of COVID-19 (including mask and vaccine mandates) using diversionary logic? How do diversions shape the policies aimed to confront the inequities that are rampant in sentencing, punishment, and deportations? These are just a small number of examples of future research that will show how diversions extend into other social domains.

Engaging in studies that highlight structural inequities, and the way advantaged groups and institutions shape social inequities, aligns with an antidiversionary approach. Using an intersectionality lens for understanding the social determinants of health aligns with antidiversionary research. Other examples of antidiversionary research can be seen in research that critiques the biomedical approaches to obesity. To challenge the biomedical constructions of obesity, Fat Studies emerged as an interdisciplinary and radical field that problematizes the dominant discourses of obesity (Cooper 2010; Levy-Navarro 2009). Reclaiming the term "fat" to remove stigma, and rejecting the medicalized term of obesity, Fat Studies scholars show how obesity is gendered, politicized, and economically motivated (Levy-Navarro 2009). Fat Studies scholars argue that a biomedical approach to obesity emphasizes individual health behaviors, lifestyle choices, diets, and the promotion of physical activity, without any recognition of how structural factors shape individuals and their health (Syed 2019). Finally, combining a feminist political economy lens with a focus on health inequalities for women has led to the creation of a new concept-the feminist political economy of health - a concept that also aligns with antidiversionary research. This concept sheds light on how women confront health inequities due to their social, economic, political, and cultural conditions (Doyal 1995; Syed 2021).

Strides are being made, as ethnic studies, feminist studies, indigenous studies, and other critical race scholars in mainstream disciplines, encourage the need to dismantle the white logic and white methods we learn through our research training (Zuberi and Bonilla-Silva 2008), and that are reproduced in the publishing enterprise and peer review process (Buggs et al. 2020). Engaging in what Rodríguez-Muñiz (2015) has described as a cultural diagnostics approach to identifying ontological myopias (the taken-for-granted assumptions that shape the research questions we ask and the overall research topics we choose) encourages the need for reflexive and critical research. Disrupting such research training allows us to dismantle Eurocentric research methods by turning the gaze toward the powerful, equipping us with ways of conducting anti-oppressive (Strega and Brown 2015) and antidiversionary research. Indeed, social science research methods would benefit from the use of Chicanx feminist methods (Hurtado 2020; Sandoval 2013), critical race 
methods (Twine and Warren 2000; Decuir-Gunby et al. 2018), indigenous and decolonial methods (Smith 2012b; Darder 2019), and intersectional methods (Abrams et al. 2020; Misra et al. 2021), that align with adopting antidiversionary approaches to research.

\section{Conclusions}

We conclude by asking how naming diversions can help us redirect research questions, research funding announcements, and the development of new measures, scales, and surveys that capture the inequality-generating behaviors of advantaged groups and institutions, leading to future datasets. We strongly believe that naming diversions will provide researchers with an opportunity to critically reflect on the way we design research studies. The naming of diversions also demonstrates the importance of interdisciplinary research that welcomes different epistemological and methodological approaches in studying immigrant health. For example, health researchers can engage with the migration, critical race theory, feminist political economy of health, intersectionality, and postcolonial scholarship to better identify inequality-generating mechanisms, and the role that advantaged groups and institutions play in shaping health inequities. Health researchers can also learn from the humanists, such as historians, to understand the history of immigration, science, and medicine, to learn how our past shapes the present time. Doing so may even provide insight into what future theoretical and methodological debates we may anticipate.

The CDC and the NIH's commitment to confronting racism, and its deleterious public health impacts, is an important first step. Yet, it remains extremely concerning and problematic that the CDC continues to implement Title 42, making its commitment to confronting racism questionable. Similarly, the lack of immigrant health studies across all stages of the knowledge production cycle mentioning white supremacy is also concerning. We sincerely hope that we, as academics, are able to use our skillset, training, and resources toward designing antidiversionary research with a goal of positively affecting the wider community.

Supplementary Materials: The following are available online at https:/ / www.mdpi.com/article/1 0.3390/socsci10090341/s1, Table S1: Coverage of Inequality Generating Behavior of Advantaged People, Self-Reports of Discrimination, and Health Behaviors/Traits in Major Nationally Representative Immigrant Health Repeat Cross-Sectional or Longitudinal Studies in the United States, Table S2: Exemplar Articles that do not Engage in Diversions.

Author Contributions: Conceptualization, S.J.G. and B.G.L.; methodology, K.M., A.O., H.F., T.T. and M.C.; software, T.T. and M.C.; validation, S.J.G.; formal analysis, T.T., M.C., K.M., A.O., H.F., S.J.G. and B.G.L.; writing-S.J.G., T.T., M.C., K.M., A.O. and B.G.L., writing-review and editing, S.J.G., T.T., M.C., K.M., A.O., H.F. and B.G.L.; supervision, S.J.G.; project administration, S.J.G.; funding acquisition, S.J.G. All authors have read and agreed to the published version of the manuscript.

Funding: This research received funding from the Chicano Studies Institute and the Faculty Research Assistance Program at the University of California, Santa Barbara.

Acknowledgments: We wish to thank the Diversions in Health Inequities Research Project team composed of students from UCSB and UCR. SJG thanks Melissa Quintela Bernice Strauss, and colleagues at UCSB, Aída Hurtado, Dolores Inés Casillas, Micaela J. Díaz-Sánchez, and Daina Sanchez for reviewing an earlier version of the paper. SJG would also like to thank her CH ST Immigration and the US-Mexico Border Spring 2021 class for listening to her lecture on diversions and for their excellent questions and feedback. Finally, SJG thanks organizers and HCOP/PCLP AltaMed Summer Internship Program participants for inviting her to present an early version of this paper and for their thoughtful questions.

Conflicts of Interest: The authors declare no conflict of interest. 


\section{References}

Abrams, Jasmine A, Ariella Tabaac, Sarah Jung, and Nicole M. Else-Quest. 2020. Considerations for employing intersectionality in qualitative health research. Social Science \& Medicine 258: 113138.

Ansley, Frances Lee. 1989. Stirring the Ashes: Race Class and the Future of the Civil Rights Scholarships. Cornell Law Review 74: 993-1077.

Asad, Asad L., and Matthew Clair. 2018. Racialized Legal Status as a Social Determinant of Health. Social Science E Medicine 199: 19-28.

Bandler, James, Patricia Callahan, Sebastian Rotella, and Kirsten Berg. 2020. Inside the Fall of the CDC. New York: ProPublica. Available online: https: / / www.propublica.org/article/inside-the-fall-of-the-cdc (accessed on 10 August 2021).

Braveman, Paula, Shiriki Kumanyika, Jonathan Fielding, Thomas Laveist, Luisa N. Borrell, Ron Manderscheid, and Adewale Troutman. 2011. Health Disparities and Health Equity: The Issue Is Justice. American Journal of Public Health 101: S149-55. [CrossRef] [PubMed]

Budiman, Abby. 2020. Key Findings about U.S. Immigrants. Washington, DC: Pew Research Center. Available online: https://www.pewr esearch.org/fact-tank/2020/08/20/key-findings-about-u-s-immigrants / (accessed on 12 August 2021).

Buggs, Shantel G., Jennifer P. Sims, and Rory Kramer. 2020. Rejecting White Distraction: A Critique of the White Logic and White Methods in Academic Publishing. Ethnic and Racial Studies 43: 1384-92. [CrossRef]

Castañeda, Heide, Seth M. Holmes, Daniel S. Madrigal, Maria-Elena D. Young, Naomi Beyeler, and James Quesada. 2015. Immigration as a Social Determinant of Health. Annual Review of Public Health 36: 375-92. [CrossRef] [PubMed]

CDC and HHS. 2020a. Order Suspending the Right to Introduce Certain Persons from Countries Where a Quarantinable Communicable Disease Exists. Federal Register. Available online: https:/ /www.federalregister.gov/documents/2020/10/16/2020-22978/ordersuspending-the-right-to-introduce-certain-persons-from-countries-where-a-quarantinable (accessed on 9 August 2021).

CDC and HHS. 2020b. CDC Director Declares Racism A 'Serious Public Health Threat': NPR. Available online: https:/ /www.npr.org/ 2021/04/08/985524494/cdc-director-declares-racism-a-serious-public-health-threat (accessed on 9 August 2021).

CDC Newsroom. 2021. Media Statement from CDC Director Rochelle P. Walensky, MD, MPH, on Racism and Health. Available online: https:/ / www.cdc.gov/media/releases/2021/s0408-racism-health.html (accessed on 1 September 2021).

Cervantes, Andrea Gómez, and Cecilia Menjívar. 2020. Legal Violence, Health, and Access to Care: Latina Immigrants in Rural and Urban Kansas. Journal of Health and Social Behavior 61: 307-23. [CrossRef]

Chavez-Garcia, Miroslava. 2012. States of Delinquency: Race and Science in the Making of California's Juvenile Justice System. Berkely: University of California Press.

Collins, Patricia Hill. 2015. Intersectionality's Definitional Dilemmas. Annual Review of Sociology 41: 1-20. [CrossRef]

Combahee River Collective. 1983. The Combahee River Collective Statement. In Home Girls: A Black Feminist Anthology. Edited by Barbara Smith. New Brunswick: Rutgers University Press, pp. 264-74.

Connor, Phillip, Jeffrey S. Passel, and Jens Manuel Krogstad. 2019. How European and U.S. Unauthorized Immigrant Populations Compare. Washington, DC: Pew Research Center. Available online: https:/ /www.pewresearch.org/fact-tank/2019/11/13/how-europeanand-u-s-unauthorized-immigrant-populations-compare/ (accessed on 12 August 2021).

Cooper, Charlotte. 2010. Fat Studies: Mapping the Field. Sociology Compass 4: 1020-34. [CrossRef]

Crenshaw, Kimberle. 1989. Demarginalizing the Intersection of Race and Sex: A Black Feminist Critique of Antidiscrimination Doctrine, Feminist Theory and Antiracist Politics. University of Chicago Legal Forum 1: 139-68.

Crenshaw, Kimberle. 1991. Mapping the Margins: Intersectionality, Identity Politics, and Violence against Women of Color. Stanford Law Review 43: 1241-300. [CrossRef]

Darder, Antonia, ed. 2019. Decolonizing Interpretive Research: A Subaltern Methodology for Social Change. London: Routledge.

Dearen, Jason, and Garance Burke. 2020. Pence Ordered Borders Closed after CDC Experts Refused. AP News. Available online: https: / /apnews.com/article/virus-outbreak-pandemics-public-health-new-york-health-4ef0c6c5263815a26f8aa17f6ea490ae (accessed on 1 September 2021).

Decuir-Gunby, Jessica T., Thandeka K. Chapman, and Paul A. Schutz, eds. 2018. Understanding Critical Race Research Methods and Methodologies: Lessons from the Field. London: Routledge.

Doyal, Lesley. 1995. What Makes Women Sick: Gender and the Political Economy of Health. Houndmills: Macmillan.

Du Bois, William Edward Burghardt. 1935. Black Reconstruction in America. New York: Routledge.

Egbert, Andi, and Kristine Liao. 2020. The Color of Coronavirus: 2020 Year in Review. St. Paul: APM Research Lab. Available online: https:/ / www.apmresearchlab.org/covid/deaths-2020-review (accessed on 1 September 2021).

Ford, Chandra L., and Collins O. Airhihenbuwa. 2010. Critical Race Theory, Race Equity, and Public Health: Toward Antiracism Praxis. American Journal of Public Health 100: S30-35. [CrossRef]

Gany, Francesca, Sehrish Bari, Pavan Gill, Rebecca Loeb, and Jennifer Leng. 2015. Step on it! Impact of a Workplace New York City Taxi Driver Health Intervention to Increase Necessary Health Care Access. American Journal of Public Health 105: 786-92. [CrossRef]

Garcia, Marc A., Patricia A. Homan, Catherine García, and Tyson H. Brown. 2021. The Color of Covid-19: Structural Racism and the Disproportionate Impact of the Pandemic on Older Black and Latinx Adult. The Journals of Gerontology: Series B 76: e75-e80. [CrossRef] [PubMed]

García, San Juanita. 2017. Racializing “Illegality": An Intersectional Approach to Understanding How Mexican-origin Women Navigate an Anti-immigrant Climate. Sociology of Race and Ethnicity 3: 474-90. [CrossRef] 
García, San Juanita. 2018. Living a Deportation Threat: Anticipatory Stressors Confronted by Undocumented Mexican Immigrant Women. Race and Social Problems 10: 221-34. [CrossRef]

Gkiouleka, Anna, Tim Huijts, Jason Beckfield, and Clare Bambra. 2018. Understanding the Micro and Macro Politics of Health: Inequalities, Intersectionality \& Institutions-A Research Agenda. Social Science E Medicine 200: 92-98.

Golash-Boza, Tanya, Maria D. Duenas, and Chia Xiong. 2019. White Supremacy, Patriarchy, and Global Capitalism in Migration Studies. American Behavioral Scientist 63: 1741-59. [CrossRef]

Gómez, Laura E. 2018. Manifest Destinies: The Making of the Mexican American Race. New York: NYU Press.

Gonzalez-Barrera, Ana, and Jens Manuel Krogstad. 2019. What We Know about Illegal Immigration from Mexico. Washington, DC: Pew Research Center. Available online: https:/ / pewrsr.ch/2FAZrIA (accessed on 9 August 2021).

Guttentag, Lucas. 2020. Coronavirus Border Expulsions: CDC's Assault on Asylum Seekers and Unaccompanied Minors. Stanford: Stanford Law School. Available online: https:/ /law.stanford.edu/2020/04/15/coronavirus-border-expulsions-cdcs-assault-on-asylum-s eekers-and-unaccompanied-minors / (accessed on 9 August 2021).

Hankivsky, Olena, and Ashlee Christoffersen. 2008. Intersectionality and the Determinants of Health: A Canadian Perspective. Critical Public Health 18: 271-83. [CrossRef]

Hardeman, Rachel R., Katy A. Murphy, J'Mag Karbeah, and Katy Backes Kozhimannil. 2018. Naming Institutionalized Racism in the Public Health Literature: A Systematic Literature Review. Public Health Reports 133: 240-49. [CrossRef] [PubMed]

Hsieh, Hsiu-Fang, and Sarah E. Shannon. 2005. Three Approaches to Qualitative Content Analysis. Qualitative Health Research 15: 1277-88. [CrossRef] [PubMed]

Hurtado, Aída. 2020. Intersectional Chicana Feminisms: Sitios y Lenguas. Tucson: University of Arizona Press.

Jones, Camara Phyllis. 2002. Confronting Institutionalized Racism. Clark Atlanta University 50: 7-22. [CrossRef]

Jones, Camara Phyllis. 2016. Launching an APHA presidential initiative on racism and health. Nation's Health 45: 3.

Kline, Nolan, and Heide Castañeda. 2020. Immigration Enforcement Policies and Latinx Health: State of Knowledge. In New and Emerging Issues in Latinx Health. Berlin: Springer International Publishing, pp. 253-69.

Kraut, Alan M. 1994. Silent Travelers: Germs, Genes, and the Immigrant Menace. Baltimore: Johns Hopkins University Press.

Kwate, Naa Oyo A., and Melody S. Goodman. 2014. An Empirical Analysis of White Privilege, Social Position and Health. Social Science \& Medicine 116: 150-60.

Landale, Nancy S., Jessica Halliday Hardie, R. Sal Oropesa, and Marianne M. Hillemeier. 2015. Behavioral Functioning among Mexican-Origin Children: Does Parental Legal Status Matter? Journal of Health and Social Behavior 56: 2-18. [CrossRef]

Lantz, Paula, Richard Lichtenstein, and Harold Pollack. 2007. Health Policy Approaches to Population Health: The Limits of Medicalization. Health Affairs (Project Hope) 26: 1253-57. [CrossRef] [PubMed]

Laster Pirtle, Whitney N., and Tashelle Wright. 2021. Structural Gendered Racism Revealed in Pandemic Times: Intersectional Approaches to Understanding Race and Gender Health Inequities in COVID-19. Gender E Society 35: 168-79.

Lebrón, Alana M. W., Amy J. Schulz, Cindy Gamboa, Angela Reyes, Edna A. Viruell-Fuentes, and Barbara A. Israel. 2018. 'They Are Clipping Our Wings': Health Implications of Restrictive Immigrant Policies for Mexican-Origin Women in a Northern Border Community. Race and Social Problems 10: 174-92. [CrossRef]

Levy-Navarro, Elena. 2009. Fattening Queer History: Where Does Fat History Go from Here? In In The Fat Studies Reader. New York: New York Univeristy Press, pp. 15-22.

Link, Bruce G., and Jo Phelan. 1995. Social Conditions As Fundamental Causes of Disease. Journal of Health and Social Behavior 35: 80-94. [CrossRef]

Link, Bruce G., and San Juanita García. 2021. Diversions: How the Underrepresentation of Research on Advantaged Groups Leaves Explanations for Health Inequalities Incomplete. Journal of Health and Social Behavior. [CrossRef]

López, Nancy, and Vivian L. Gadsden. 2016. Health Inequities, Social Determinants, and Intersectionality. In NAM Perspectives. Discussion Paper. Washington, DC: National Academy of Medicine. [CrossRef]

Lopez, William D. 2019. Seperated: Family and Community in the Aftermath of an Immigration Raid. Baltimore: Johns Hopkins University Press.

Lynch, Julia. 2017. Reframing Inequality? The Health Inequalities Turn as a Dangerous Frame Shift. Journal of Public Health 39: 653-660. [CrossRef]

Malat, Jennifer, Sarah Mayorga-Gallo, and David R. Williams. 2018. The Effects of Whiteness on the Health of Whites in the USA. Social Science $\mathcal{E}$ Medicine 199: 148-56.

Mann-Jackson, Lilli, Eunyoung Y. Song, Amanda E. Tanner, Jorge Alonzo, Julie M. Linton, and Scott D. Rhodes. 2018. The Health Impact of Experiences of Discrimination, Violence, and Immigration Enforcement among Latino Men in a New Settlement State. American Journal of Men's Health 12: 1937-47. [CrossRef]

Markel, Howard, and Alexandra Minna Stern. 1999. Which Face? Whose Nation? American Behavioral Scientist 42: 1314-31. [CrossRef]

Martínez, Airín D., Lillian Ruelas, and Douglas A. Granger. 2018. Household Fear of Deportation in Relation to Chronic Stressors and Salivary Proinflammatory Cytokines in Mexican-Origin Families Post-SB 1070. SSM—Population Health 5: 188-200.

Mills, Charles W. 1997. The Racial Contract. Ithaca: Cornell University Press.

Mills, Charles W. 2003. White Supremacy as Sociopolitical System: A Philosophical Perspective. In White Out: The Continuing Significance or Racism, 1st ed. London: Routledge, pp. 35-48. 
Minkler, Meredith, Alicia L. Salvatore, Charlotte Chang, Megan Gaydos, Shaw San Liu, Pam Tau Lee, Alex Tom, Rajiv Bhatia, and Niklas Krause. 2014. Wage Theft as a Neglected Public Health Problem: An Overview and Case Study From San Francisco's Chinatown District. American Journal of Public Health 104: 1010-20. [CrossRef] [PubMed]

Misra, Joya, Celeste Vaughan Curington, and Venus Mary Green. 2021. Methods of Intersectional Research. Sociological Spectrum 41: 9-28. [CrossRef]

Molina, Natalia. 2006. Fit to Be Citizens? Public Health and Race in Los Angeles, 1879-1939. Berkely: University of California Press.

Molina, Natalia. 2011. Borders, Laborers, and Racialized Medicalization Mexican Immigration and US Public Health Practices in the 20th Century. American Journal of Public Health 101: 1024-31. [CrossRef]

Morey, Brittany N. 2018. Mechanisms by Which Anti-Immigrant Stigma Exacerbates Racial/Ethnic Health Disparities. American Journal of Public Health 108: 460-63. [CrossRef] [PubMed]

Navarro, Vicente. 2009. What We Mean by Social Determinants of Health. International Journal of Health Services 39: 423-41. [CrossRef]

Novak, Nicole L, Arline T. Geronimus, and Aresha M. Martinez-Cardoso. 2017. Change in Birth Outcomes among Infants Born to Latina Mothers after a Major Immigration Raid. International Journal of Epidemiology 6: 839-49.

Ornelas, India J, Thespina J Yamanis, and Raymond A Ruiz. 2020. The Health of Undocumented Latinx Immigrants: What We Know and Future Directions. Annu Rev Public Health 41: 289-308. [CrossRef]

Park, Lisa Sun-Hee, Anthony Jimenez, and Erin Hoekstra. 2017. Decolonizing the U.S. Health Care System: Undocumented and Disabled after ACA. Health Tomorrow: Interdisciplinarity and Internationality 5: 24-54.

Perreira, Krista M., and Juan M. Pedroza. 2019. Policies of Exclusion: Implications for the Health of Immigrants and Their Children. Annual Review of Public Health 40: 147-66. [CrossRef]

Phelan, Jo C., and Bruce G. Link. 2015. Is Racism a Fundamental Cause of Inequalities in Health? Annual Review of Sociology 41: 311-30. [CrossRef]

Pilkington, Ed. 2021. Outcry as More than 20 Babies and Children Deported by US to Haiti I US Immigration. The Guardian. Available online: https: / www.theguardian.com/us-news/2021/feb/08/us-ice-immigration-customs-enforcement-haiti-deportations (accessed on 12 August 2021).

Rodriguez, Javier M. 2019. The Politics Hypothesis and Racial Disparities in Infants' Health in the United States. SSM-Population Health 8: 100440. [CrossRef] [PubMed]

Rodríguez-Muñiz, Michael. 2015. Intellectual Inheritances: Cultural Diagnostics and the State of Poverty Knowledge. American Journal of Cultural Sociology 3: 89-122. [CrossRef]

Romero, Mary. 2008. The Inclusion of Citizenship Status in Intersectionality: What Immigration Raids Tells Us About Mixed-Status Families, the State and Assimilation. International Journal of Sociology of the Family 34: 131-52.

Sáenz, Rogelio, and Karen Manges Douglas. 2015. A Call for the Racialization of Immigration Studies. Sociology of Race and Ethnicity 1: 166-80. [CrossRef]

Sáenz, Rogelio, and Trinidad Morales. 2012. The Latino Paradox. In The Demography of the Hispanic Population: Selected Essays. Charlotte: Information Age Publishing, pp. 47-73.

Salas, Lorraine Moya, Cecilia Ayón, and Maria Gurrola. 2013. Estamos Traumados: The Effect Of Anti-Immigrant Sentiment And Policies On The Mental Health Of Mexican Immigrant Families. Journal of Community Psychology 41: 1005-20. [CrossRef]

Sandoval, Chela. 2013. Methodology of the Oppressed. Tucson: University of Arizona Press, vol. 18.

Schwartz, Donald. 2004. Race and Membership in American History: The Eugenics Movement I History Cooperative. Available online: https://www.facinghistory.org/books-borrowing/race-and-membership-american-history-eugenics-movement (accessed on 12 August 2021).

Smith, Andrea. 2012a. Indigeneity, Settler Colonialism, White Supremacy. Racial Formation in the Twenty-First Century. Berkely: University of California Press.

Smith, Linda Tuhiwai. 2012b. Decolonizing Methodologies: Research and Indigenous Peoples, 2nd ed. London: Zed Books.

Speed, Shannon. 2019. Incarcerated Stories: Indigenous Women Migrants and Violence in the Settler-Capitalist State. Chapel Hill: UNC Press Books.

Strega, Susan, and Leslie Brown, eds. 2015. Research as Resistance: Revisiting Critical, Indiginous, and Anti-Oppressive Approaches, 2nd ed. Toronto: Canadian Scholars' Press Inc.

Syed, Iffath Unissa. 2019. In Biomedicine, Thin Is Still In: Obesity Surveillance among Racialized, (Im)Migrant, and Female Bodies. Societies 9: 59. [CrossRef]

Syed, Iffath Unissa. 2021. Feminist Political Economy: Current Perspectives and Future Directions. Healthcare 9: 233. [CrossRef] [PubMed]

Treitler, Vilna Bashi. 2015. Social Agency and White Supremacy in Immigration Studies. Sociology of Race and Ethnicity 1: 153-65. [CrossRef]

Twine, France Winddance, and Jonathan Warren, eds. 2000. Racing Research, Researching Race Methodological Dilemmas in Critical Race Studies. Chicago: NYU Press.

U.S. Customs and Border Protection. 2021. Southwest Land Border Encounters. Available online: https://www.cbp.gov/newsroom/s tats/southwest-land-border-encounters (accessed on 10 August 2021).

UN High Commissioner for Refugees (UNHCR). 2020. Key Legal Considerations on Access to Territory for Persons in Need of International Protection in the Context of the COVID-19 Response. Available online: https://www.refworld.org/docid/5e71328 34.html (accessed on 12 August 2021). 
Vargas, Edward D., Gabriel R. Sanchez, and Melina Juárez. 2017. Fear by Association: Perceptions of Anti-Immigrant Policy and Health Outcomes. Journal of Health Politics, Policy and Law 42: 459-83. [CrossRef] [PubMed]

Viruell-Fuentes, Edna A. 2007. Beyond Acculturation: Immigration, Discrimination, and Health Research among Mexicans in the United States. Social Science E Medicine 65: 1524-35.

Viruell-Fuentes, Edna A. 2011. "IT'S A LOT OF WORK": Racialization Processes, Ethnic Identity Formations, and Their Health Implications. Du Bois Review: Social Science Research on Race 8: 37-52. [CrossRef]

Viruell-Fuentes, Edna A., Patricia Y. Miranda, and Sawsan Abdulrahim. 2012. More than Culture: Structural Racism, Intersectionality Theory, and Immigrant Health. Social Science \& Medicine 75: 2099-2106. [CrossRef]

Walia, Harsha. 2021. Border and Rule: Global Migration, Capitalism, and the Rise of Racist Nationalism. Chicago: Haymarket Books.

Wallace, Steven P., Maria-Elena De Trinidad Young, Michael A. Rodríguez, and Claire D. Brindis. 2019. A Social Determinants Framework Identifying State-Level Immigrant Policies and Their Influence on Health. SSM-Population Health 7: 100316. [CrossRef]

Warner, Tara D., and Raymond R. Swisher. 2015. Adolescent Survival Expectations: Variations by Race, Ethnicity, and Nativity. Journal of Health and Social Behavior 56: 478-94. [CrossRef]

Williams, David R., and Selina A. Mohammed. 2013. Racism and Health I: Pathways and Scientific Evidence. American Behavioral Scientist 57: 1152-73. [CrossRef] [PubMed]

Williams, David R., Jourdyn A. Lawrence, and Brigette A. Davis. 2019. Racism and Health: Evidence and Needed Research. Annual Review of Public Health 40: 105-25. [CrossRef] [PubMed]

World Health Organization. 2008. Closing the Gap in a Generation: Health Equity Through Action on the Social Determinants of HealthFinal Report of the Commission on Social Determinants of Health. Geneva: World Health Organization. Available online: https: //www.who.int/publications/i/item/WHO-IER-CSDH-08.1 (accessed on 10 August 2021).

Zuberi, Tukufu, and Eduardo Bonilla-Silva, eds. 2008. White Logic, White Methods: Racism and Methodology. Lanham: Rowman \& Littlefield Publishers. 